\title{
Discriminatory Immigration Bans Elicit Anti-Americanism in Targeted Communities: Evidence from Nigerian Expatriates
}

\author{
Aaron Erlich $^{1 \star}\left(\mathbb{D}\right.$, Thomas Soehl ${ }^{1}$ (D) and Annie Y. Chen ${ }^{1,2}$ \\ ${ }^{1}$ McGill University, Montréal, Canada and ${ }^{2}$ Dartmouth College, Hanover, USA \\ ${ }^{\star}$ Corresponding author. Email: aaron.erlich@mcgill.ca.
}

\begin{abstract}
Do discriminatory US immigration policies affect foreign public opinion about Americans? When examining negative reactions to US actions perceived as bullying on the world stage, existing research has focused either on US policies that involve direct foreign military intervention or seek to influence foreign countries' domestic economic policy or policies advocating minority representation. We argue that US immigration policies especially when they are perceived as discriminatory - can similarly generate antiAmerican sentiment. We use a conjoint experiment embedded in a unique survey of Nigerian expatriates in Ghana. Comparing respondents before and after President Trump surpisingly announced a ban on Nigerian immigration to the United States, we find a large drop (13 percentage points) in Nigerian's favorability towards Americans.
\end{abstract}

Keywords: Unexpected survey design; conjoint experiment; Nigeria; Ghana; migration; immigration ban; anti-Americanism

On January 31, 2020 President Donald Trump surprisingly announced a ban on the issuance of all US visas leading to Nigerian citizens' permanent residence in the USA. ${ }^{1}$ We analyze the effect of Trump's announcement on a sample of Nigerian expatriates in Ghana.

Our study contributes to a line of research that has documented a number of instances where US foreign policy has generated anti-American sentiment - especially in cases where US policies are seen as infringing on national sovereignty of the

D- This article has earned badges for transparent research practices: Open Data and Open Materials. For details see the Data Availability Statement.

We thank Aengus Bridgman, Patrick Kwasi Brobbey, Costin Ciobanu, David FitzGerald, Nicholas Kerr, and members of our respective research groups for feedback on earlier drafts of the paper. We thank Favour Daka for excellent research assistance. The research was carried out under Research Ethics Board approval \#92-0719.

${ }^{1}$ The US also applied the same rules to citizens of Myanmar, Eritrea, and Kyrgyzstan and suspended diversity lottery visas for Sudan and Tanzania (Kanno-Youngs 2020).

(C) The Author(s) 2021. Published by Cambridge University Press on behalf of The Experimental Research Section of the American Political Science Association. 
targeted countries. Clear examples include US military interventions such as those in Iraq or Syria, which are associated with an increase in antipathy toward the USA and its citizens across many of the countries of Middle East (Chiozza 2006; Jamal et al. 2015). Other foreign policy cases include those where the US deploys its power to remake economic (Sokolov et al. 2018) or gender relations (Bush and Jamal 2015).

We argue that restrictive immigration policies that target specific countries or groups such as the immigration ban enacted by the Trump administration can similarly increase anti-American sentiment. Indeed, the fact that the ban singled out specific countries plays a central role in our argument. Since all countries control borders and restrict migration, most people would not notice or react to normal changes in immigration policy. However, policies, like those announced by the Trump administration, that single out specific countries (or ethnic groups) create what FitzGerald and Cook-Martín $(2015,27)$ call the "politics of international humiliation." The US did not exclude Nigerians because they lack requisite skills, education, or family ties. Instead, the US categorically excluded them as Nigerians. ${ }^{2}$

While common throughout the first half of the 20th century, immigration policies discriminating by national origin or ethnicity are now widely viewed as violating liberal principles and outside the legitimate realm of immigration policy (Joppke 2005). So, rather than an instance of normal immigration policy, which would concern only those directly affected (in our case, those planning to move to the US), discriminatory immigration bans are an assault to the banned country's national honor and international reputation. Since nations are status groups that offer their members national prestige as a symbolic resource (Finlayson 1998), citizens may interpret the devaluation of that group identity as a threat to their self-worth. A long line of lab-based social-psychology research demonstrates that individuals show more in-group bias and negative attitudes towards out groups in response to collective social identity devaluation (for a review see Ellemers, Spears, and Doosje 2002). People may also try to repair the tarnished group identity and embark on strategies to differentiate their group. Strategies may include derogating outgroup members - especially when individuals are highly committed to a threatened identity that they believe is of high status (Branscombe and Wann 1994). When it comes to national identity, perceived threats to the national group's position can also increase hubris - the belief that one's own country is better than others (Feinstein 2016). Similarly, research in the US shows that maintaining the honor of the national community and a reputation for resolve is a main driver of public opinion on administrations' reactions to international security incidents (Snyder and Borghard 2011). We argue that discriminatory immigration bans that single out specific countries as undesirable will set off similar reactions.

To support our argument, we draw on a unique survey of Nigerian expatriates in Ghana. Critically, we conducted our survey both before and after the US announced the Nigerian immigration ban, and the survey instrument contained a conjoint experiment measuring attitudes towards potential new neighbors - a commonly used metric for social affinity (Schachter 2016; Auerbach and Thachil 2018). In the conjoint

\footnotetext{
${ }^{2}$ The ban's official justification was that the targeted countries did not meet the Department of Homeland Security's “identity management, information sharing, national security, and public safety assessment criteria” (https://bit.ly/2S9T9sG).
} 
experiment, one neighbor option is "Americans," which allows us to estimate any decrease in affinity toward American neighbors (increased anti-Americanism) as a result of the ban. Our conceptualization of anti-American attitudes is in line with recent work that has acknowledged the multi-dimensional nature of antiAmericanism. We follow Chiozza $(2009,37)$, who views anti-Americanism as an "ideational phenomenon," which leads to citizens' outside the USA' to hold "American citizens, American democracy, American society, American values, or American symbols" in low opinion. We focus in this article on the effect of targeted policies (what the US does) $)^{3}$ on attitudes towards American citizens.

\section{Research design}

We estimate the effect of the announcement of the United States' immigration ban on attitudes towards Americans by comparing Nigerian expatriates in Ghana who completed our survey before the immigration ban's announcement - data collected initially as a pretest that we launched in mid-December 2019 - to those who were recruited during the main phase of data collection in February 2020. This causal identification strategy, also known as the "Unexpected Event during Survey" (UEDS) design (Muñoz, Falcó-Gimeno, and Hernández 2020), capitalizes on the fact that whether or not a respondent completed our survey before or after the event in question is as-if random with respect to the timing of the event. Thus, the group surveyed prior to the event serves as a control group to those surveyed after the event (the treatment group). Scholars have used this strategy to estimate the effects of a wide range of events including the effect of terrorist attacks on electoral outcomes (Balcells and Torrats-Espinosa 2018) and attitudes towards immigrants (Legewie 2013; Eady and Breton 2021) as well as the effect of an immigrantintegration-related court case on electoral outcomes (Bridgman et al. 2021). Appendix Table A-1 in Supplementary material shows the balance for a range of variables between the two samples, including media consumption, providing support that treatment is as-if randomly assigned.

One key identification assumption for the UEDS strategy to support causal claims is that the event, as indicated in the name of the design, must be unexpected. In order for the pre-event survey group to function as a control group, it cannot have any exposure to the event, which would be the case if the event was widely anticipated. In the case of the immigration ban against Nigerians, solid evidence exists that the announcement was unexpected. While global media widely prognosticated that the USA would implement further travel and immigration restrictions against some countries, Nigeria's presence on the list of countries whose citizens were now excluded was surprising. Even Nigeria's top diplomat was "blindsided with the announcement of the visa restrictions by the U.S” (New York Times Feb 4, 2020). Appendix B in Supplementary material contains further reporting from Nigeria to bolster this claim.

General citizen internet users also do not appear to have expected the ban. Google trends data (see Figure 1) show essentially no search activity for the words "travel ban" before late January and then a large spike on February 1,

${ }^{3}$ Rubinstein and Smith $(1988,38-39)$ call these "Issue-Oriented" motives. 


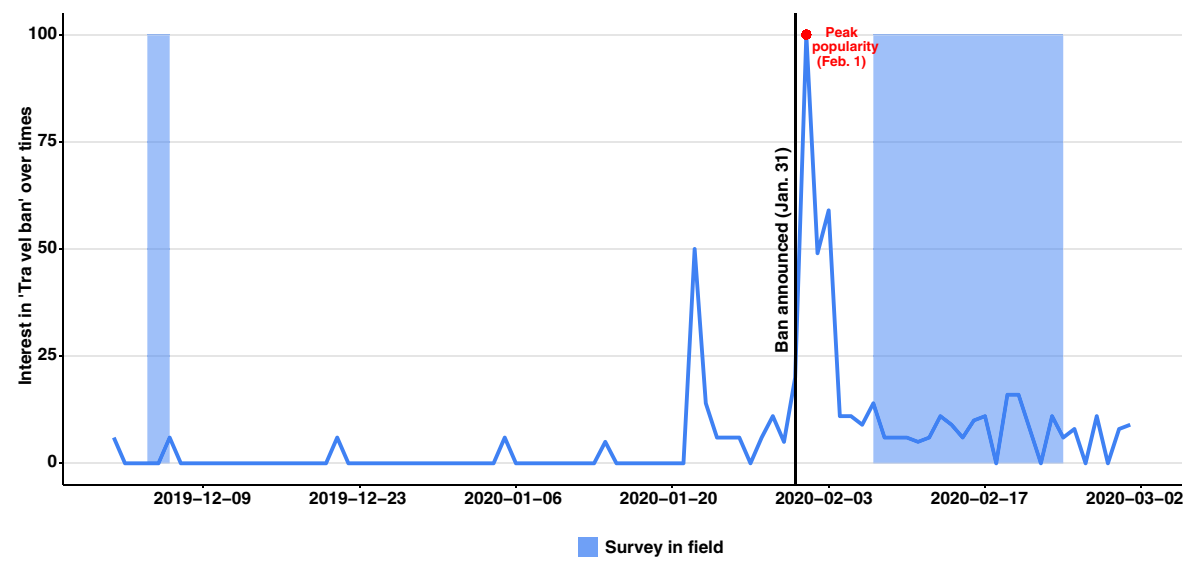

Figure 1

Google Search Trends for "Travel Ban" in Nigeria. The $y$-axis reflects search interest relative to the highest point (February 1) from December 1, 2019 to March 1, 2020. A value of 100 denotes the peak popularity for the search query in this period.

2020. ${ }^{4}$ Interest in the ban experienced a smaller surge (on January 22, 2020) just prior to the official White House statement (on January 31, 2020) because reports anticipating the announcement had surfaced at this time. We do not expect this to have any meaningful impact on our analysis since the pretest data was collected prior to this early leak.

Corresponding to the condition that the pre-event respondents were not partially "treated" by anticipating the event, the postevent respondents should all have been exposed to the event. Given the importance of migration amongst Nigerians, we assume the immigration ban was a salient enough event that most Nigerians would have paid attention. Indeed, on February 1st, 2020, the news was front page "breaking news" on several major Nigerian news sites. We also searched six main Nigerian daily news publications, and all of them covered the Nigerian immigrant ban within the first week of its announcement. Although our respondents do not reside in Nigeria, the majority of them follow news in Nigeria: about $70 \%$ of our respondents spend at least 30 min per day following news from Nigeria while only $12 \%$ state they do not follow Nigerian news at all. These numbers are in line with research that shows that most expatriates follow news in their home country and do so using online versions of home-country media (Christiansen 2004; Mattelart 2009; Waldinger 2015). We note that lack of knowledge of the ban would likely only work against us finding any treatment effect. We explore this option in additional analyses summarized in Appendix C, Supplementary material, disaggregating our sample by media consumption. ${ }^{5}$

\footnotetext{
${ }^{4}$ Though technically an "immigration ban," we use the search term "travel ban" because it is more colloquially used. Related terms, such as "immigration ban" and "Trump ban," were less commonly searched in Nigeria, according to Google Trends. A similar pattern emerges for the same terms in Ghana.

${ }^{5} \mathrm{We}$ also note that we do not see any indication that those in our Post-Ban sample were more closely following media than the Pre-Ban sample as a result of the ban (see Appendix Table A-1 in Supplementary material).
} 
Finally, causal identification requires that there was no other event in the period between our pre- and post-ban samples that could have caused a change in attitudes towards Americans, leading us to wrongly attribute any changes we observe. To examine this assumption, we use the Wayback Machine to build a database of all of the top stories present on the website of one of Nigeria's most popular national daily newspapers (The Punch). We supplemented this analysis through a content analysis of all Nigerian and Ghanaian news on Lexis-Nexis, which contained the word "United States" AND/OR "Trump." We find only one potential story that could have had an effect: the killing of Qassem Soleimani on January 3rd. In Appendix D in Supplementary material, we further document our methods for investigating potential events, explain why we believe the Soleimani assassination is unlikely to have shifted Nigerians' opinions, and conduct a robustness check by using a Christian-only subsample.

\section{Data and methods}

Social media companies such as Facebook collect and construct detailed data about their users. These data include demographic characteristics such as age, gender, location, and language use, but also information such as interests and, in some cases, professional background. Researchers have used targeted Facebook advertising to conduct surveys of employees at specific firms (Schneider and Harknett 2019), and groups with specific demographic (Arcia 2014) or political (Jäger 2017) characteristics, demonstrating that social media allows researchers to study very specific and otherwise hard-to-reach populations. Critically for our project, Facebook provides advertisement categories on "expatriates" such as Nigerians living in Ghana. The "expatriate" group has been shown to provide a good proxy for emigrant/ migrant populations (Zagheni, Weber, and Gummadi 2017) and has been used to survey them (e.g. Pötzschke and Braun 2017).

We recruited our sample in Ghana via targeted Facebook advertisements of Nigerians in Ghana using the "expatriate" advertising target category provided by Facebook. When Nigerian Facebook users in Ghana clicked on the advertisement, they were directed to our study, which we carried out via Qualtrics. In total, we conducted three advertising campaigns. A pilot campaign (wave 1), lasting two days, took place from December 4, 2019 to December 6, 2019 and drew 129 respondents; these are the pre-event respondents. The next campaign, beginning February 7, 2020, ran for 10 days (wave 2) and was immediately followed by a 7-day campaign (wave 3), which was active until February 24, 2020. ${ }^{6}$ While we made small adjustments to the survey content based on the pretest, the conjoint experiment module was not changed between survey periods. In the second and third campaigns combined, we recruited 598 respondents. Further survey information, including a CONSORT flow chart, is found in Appendix E, Supplementary material.

To the best of our knowledge, no comprehensive demographic data exist for Nigerians in Ghana. Thus, we cannot evaluate the extent to which our sample is

${ }^{6}$ Waves 2 and 3 differ only in the ad delivery strategy deployed (Landing Page Views vs. Link Clicks). 
representative of the Nigerian population in Ghana. ${ }^{7}$ That said, we have substantial variation across demographic variables (See Appendix A in Supplementary material). Moreover, we used the same sampling technique to conduct a survey of Nigerians in Canada (not reported on in this study) and comparisons to Canadian Census data suggest good representativeness with respect to gender, age, and education.

Reflecting the facts that the young undertake migration and our survey excludes minors under the age of 18 , the median respondent in our sample is 31 years old. Though we could not find reliable statistics on the gender ratio of Nigerian expatriates in Ghana, according to our sample, males predominate (71\%). Our sample is also highly educated: $70 \%$ have at least some post-secondary education. Overall, relatively recent emigrants compose the bulk of our sample: the median respondent reported leaving Nigeria 5 years ago. Correspondingly, respondents generally maintain close ties to Nigeria: almost half of the respondents indicate they call their families in Nigeria at least several times a week, and over $60 \%$ report sending money back home.

We designed our survey to measure Nigerian emigrants' attitudes in countries across the globe, including Canada, South Africa, the United Arab Emirates, and others. To that end, the survey instrument included a host of questions related to respondents' migration history, cross-border ties, and attitudes towards Nigerian politics. Critically for this study of Nigerian expatriates in Ghana, the survey also included a conjoint experiment, originally designed to understand how Nigerian expatriates in different contexts vary their preferences for different types of neighbors, which allows us to assess Nigerians' favorability towards Americans.

In our conjoint experiment, we present respondents with profiles of two hypothetical neighbors. Each of these neighbors has randomized values of the same four attributes. In addition to ethnicity/nationality - the focal item for this analysis - we included family status, occupation, and religion. The ethnicity/nationality attribute had seven different possible values. Three options were the largest Nigerian ethnic groups (Igbo, Yoruba, Hausa), and a fourth option was a Nigerian with no ethnic identity given. A fifth option was Ghanaian - a member of the host country majority. The final two were other migrant groups: Togolese, who are nationals of a country bordering both Nigeria and Ghana, and American, which we included as a reference category for possible cross-country comparisons.

After seeing the profiles, respondents were asked to choose which of the two neighbors they preferred. Additionally, we asked each respondent to separately rate on a 1-7 scale how much they would like to have each person as a neighbor.

Our survey asks each respondent to complete four conjoint choice tasks - well below the maximum number seen as feasible (Bansak et al. 2018). Figure 2 portrays a sample conjoint task. ${ }^{8}$ To minimize order effects, the attribute order is randomized across respondents but remains constant for each participant to reduce cognitive burden. $^{9}$

\footnotetext{
${ }^{7}$ Beyond the lack of demographic data, we are only aware of one other survey of Nigerians in Ghana, which focuses on a particular group of subjects (Adida 2014).

${ }^{8}$ Mobile optimizations explain why the word "Neighbor" contains a space, which permits word wrapping so that text can fit on mobile phone screens.

${ }^{9}$ We find no evidence of of profile order $(F(3020,3027)=0.95, p=0.47)$ or carryover effects in the sample $(F(3020,3027)=0.52, p=0.96)$.
} 


$\begin{array}{ccc}\begin{array}{c}\text { Neighbor A } \\ \text { Large extended family }\end{array} & \text { Family } & \text { Neighbor B } \\ \text { Igbo } & \text { Ethnicity } & \text { With a spouse } \\ \text { Street vendor } & \text { Occupation } & \text { Togolese } \\ \text { Muslim } & \text { Religion } & \text { Engineer } \\ & & \text { Muslim }\end{array}$

\section{If you had to choose between them, which of these two neighbors do you prefer?}

Neighbor A

Neighbor B

How much would you like to have this person as a neighbor?

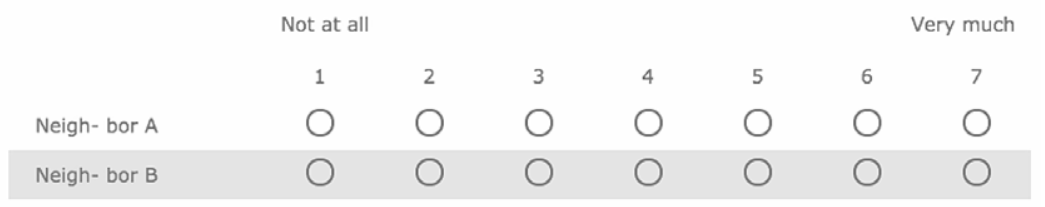

Figure 2

Sample conjoint task.

Of our respondents, a total of 394 (80 in the pre-ban period and 314 in the postban period) persisted until the conjoint experiment, which was situated near the end of the survey. Since each respondent evaluated eight neighbor profiles, after omitting unanswered conjoint tasks, there are a total of 3,034 observations across the pre- and post-ban period for the forced-choice outcome, and 2,788 observations for the rating outcome.

\section{Analysis and results}

In conjoint analysis, attributes' marginal means are average outcomes for each level of the attribute, all else equal. Per the UEDS design, we exploit the ban as an exogenous shock to identify the causal effect of the ban on favorability towards Americans among Nigerian expatriates. The effect is estimated by differencing the marginal means for participant responses before and after January 31st.

Formally, $Y$ is the outcome (forced binary choice or rating), $A \in$ $\{$ American, Nigerian, ..., Igbo $\}$ is the ethnicity/nationality attribute, $X$ represents all other attributes in the conjoint (occupation, family, religion) and the non-American levels of the ethnicity/nationality attribute, and $T \in\{0,1\}$ denotes the treatment period, the difference between pre- and post-ban periods is $\bar{Y}_{t=1 \mid a=A \text { merican }}-\bar{Y}_{t=0 \mid a=\text { American }}$, which we estimate as $\left(\alpha_{1}+\beta_{1}+\delta_{1}\right)-\left(\alpha_{2}+\beta_{2}+\delta_{2}\right)$ from the following models:

$$
\widehat{Y}=\alpha_{1}+\beta_{1} A_{\text {American }}+\boldsymbol{X} \delta_{1}+\varepsilon \text {, for all } t=0
$$




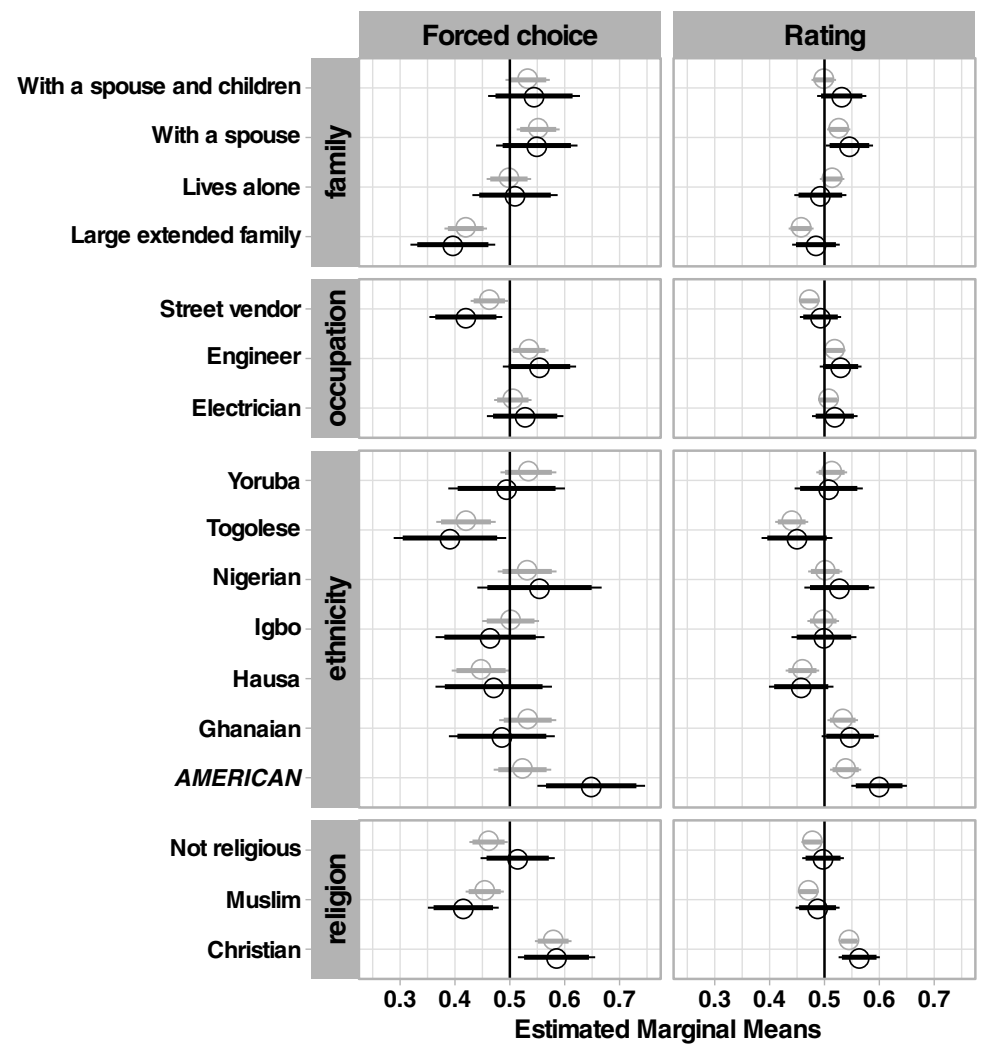

Figure 3

Marginal means of attributes in neighbor choice and rating by pre- and post-ban period. Black and grey circles represent pre- and post-ban estimates, respectively. Thick horizontal lines represent $90 \%$ confidence intervals. Thin lines are $95 \%$ confidence intervals.

$$
\widehat{Y}=\alpha_{2}+\beta_{2} A_{\text {American }}+\boldsymbol{X} \delta_{2}+\varepsilon, \text { for all } t=1
$$

Standard errors for each marginal mean are clustered by respondent.

Figure 3 displays the marginal means of all attribute levels at $90 \%$ and $95 \%$ confidence levels grouped by pre- and post-ban period for forced-choice and rating outcomes. As the literature expects (Duncan, Moehler, and Silver 2015), Americans constituted the most popular potential neighbor group in the pre-ban period (marginal mean of 0.65 ). In the post-ban period, American popularity declined to 0.52 . Preferences for other groups were as one would expect: engineers are substantially more popular than street vendors as potential neighbors; large extended families are disfavored over couples or families; and, since our sample is predominantly Christian (as is the host country Ghana), unsurprisingly, there exists a strong preference for Christian neighbors over Muslims.

Figure 4 focuses on the differences for the ethnicity and national origin attribute and shows the 13 percentage point reduction in marginal preference for Americans is statistically significant. Moreover, the difference is only significant in the 


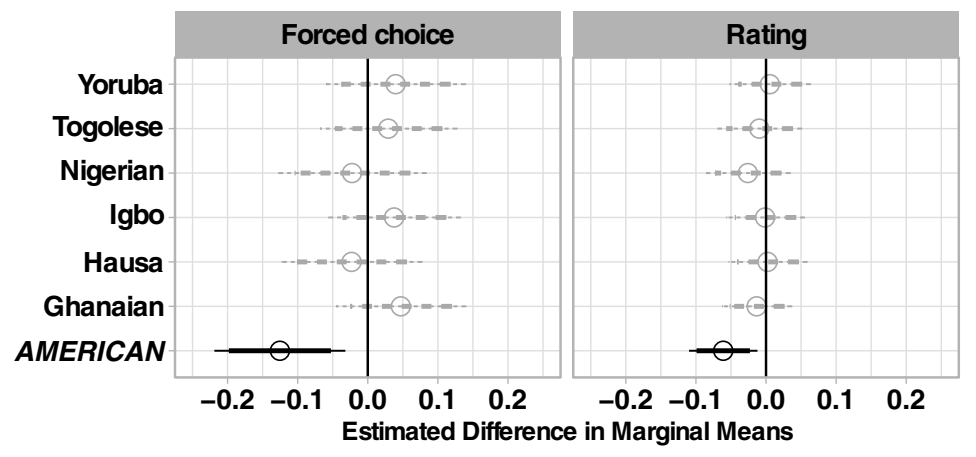

Figure 4

Change in the evaluation of potential neighbors by ethnicity/nationality between the pre- and post-ban periods. Thick horizontal lines represent $90 \%$ confidence intervals. Thin lines are $95 \%$ confidence intervals.

American group. That no other group witnessed a negative reaction is worth highlighting because it provides evidence that what we observe here is a backlash against Americans specifically rather than a more generalized rallying around national identity and increased distrust of members of all out groups.

Based on all three waves pooled, this 13-point difference is approximately the same size as the difference in preferences for having a "Christian" versus "Muslim" neighbor (13.5 points), and larger than the difference between a neighbor who is an "Engineer" as opposed to a "Street vendor" (8.5 points).

An examination of rating outcomes, which range from 1 to 7 , reveals nearidentical patterns. Figures 3 and 4 present rescaled rating marginal means and differences in these means, respectively, created by collapsing the original 7-point scale to one that ranges from 0 to 1 . The average rating for American neighbors drops by 0.43 (from 5.20 to 4.77 on the original scale). This effect corresponds to a 0.24 standard deviation decrease from the pretreatment distribution of ratings. Both the rating and the choice results are robust to dropping problematic respondents (see Appendix F in Supplementary material). We further discuss the sensitivity of our results in Appendix G, Supplementary material.

\section{Discussion and conclusion}

How do those who are the target of discriminatory immigration restrictions react to being excluded? As we show, discriminatory migration policies can provoke a backlash among citizens of the targeted country (in our case, Nigeria). This finding bolsters previous work on anti-American sentiment that finds a tight link between how respondents think about the USA and how they feel about its people (Chiozza 2006, 96). In sum, while rank-and-file American nationals are not directly responsible for the immigration ban and may not agree with it, in the eyes of many Nigerians, they represent the actions of the American state. Belligerent American foreign policy, especially in the Middle East since 9/11, has significantly lowered the approval 
of the USA (124). Our results suggest that discriminatory immigration policies may play a similar role, at least among some populations.

While the combination of a conjoint experiment administered both before and after the immigration ban and the unexpected nature of its announcement affords a unique opportunity to identify the effect these policies have on those they target, we note a few caveats and scope conditions of our reseach. Our sample - Nigerians who emigrated to Ghana - are clearly a select subset of Nigerians. Whether a representative sample of Nigerians in Nigeria would have yielded a stronger or weaker effect, we cannot ultimately answer. Arguably, as emigrants, our respondents may feel most directly targeted by immigration bans and may be most attuned to migration policy - raising the possibility that our findings are an overestimate relative to the effect one might find among Nigerians on average. However, in the case of Nigeria, even expatriates alone comprise a non-trivial population. While numbers are hard to pinpoint, between 5 and 20 million Nigerians currently reside outside Nigeria (OECD 2015; Ogen 2017). Moreover, migration appears to be on the mind of many Nigerians; a Pew Global Attitudes survey in 2018 found that $45 \%$ of Nigerians planned to leave Nigeria. ${ }^{10}$

As we argue, the Trump migration ban does not constitute a case of normal migration policy; banning Nigerians as members of a nation state is an affront to their national honor. In fact, we would not expect to see the kind of backlash against Americans from normal changes in migration policy. Taken as an instance of national humiliation, our estimate might be a lower bound. As emigrants, those sampled have, by "voting with their feet," acted in a way that reflects a distrust of the Nigerian state. Consonant with findings of other emigrant populations (Acosta et al. 2012; Waldinger 2015, 91), our sample holds considerably more negative attitudes towards the Nigerian government than the Afrobarometer's representative survey in Nigeria (see Appendix H in Supplementary material, which shows that, even when we demographically match our respondents to similar respondents from the Afrobarometer, our sample is much more negative toward Nigeria). Consequently, we would expect our sample to react less strongly than the average Nigerian.

We also highlight that unlike the Trump administration's previous "Muslim Bans," this ban did not claim to target Nigerians because of their religion (approximately half of Nigerians are Muslim with the other half Christian) but targeted Nigerians as nationals. The composition of our sample also supports a conclusion that this was chiefly about national identity rather than a backlash against antiMuslim discrimination and supports our argument that what we find here is indeed a reactive nationalism. Matching the religious makeup of Ghana's majority Christian population, the Nigerian expatriate population in Ghana is overwhelmingly Christian, and correspondingly only $10 \%$ of our sample are Muslim.

Finally, we note that like much of sub-Saharan Africa (Duncan, Moehler, and Silver 2015), Nigerians have generally viewed the USA positively even under the Trump presidency. ${ }^{11}$ This positive view of the US means that, prior to the ban, there

\footnotetext{
${ }^{10}$ See https://bit.ly/3eBNJze.

${ }^{11}$ A 2018 Pew Research Centre Poll found that 58\% of Nigerians stated confidence in Donald Trump's handling of world affairs as compared to a median of $27 \%$ in 32 other countries surveyed (Pew Research Centre 2018).
} 
was not a floor on a negative reaction to a statement made by the Trump administration. Unfortunately, our data do not allow us to say whether or not the effects we identified lasted beyond the immediate aftermath of the policy announcement or whether Nigerians returned to the strikingly positive evaluations of Americans we observed before the discriminatory migration policy went into effect.

Supplementary Material. To view supplementary material for this article, please visit https://doi.org/10. 1017/XPS.2021.26

Data Availability Statement. The data, code, and any additional materials required to replicate all analyses in this article are available at the Journal of Experimental Political Science Dataverse within the Harvard Dataverse Network, at: https://doi.org/10.7910/DVN/V8NM9T.

Financial Support. Support for this research was provided by the Social Science and Humanities Research Council (SSHRC) Insight Development Grant, award no. 430-2018-0533.

Conflict of Interest. The authors declare that there is no conflict of interest.

\section{References}

Acosta, Rafael Alarcón, Luis Escala Rabadan, Olga Odgers Ortiz, and Roger Waldinger. 2012. Mudando el hogar al norte: trayectorias de integración de los inmigrantes mexicanos en los Ángeles. El Colegio de la Frontera Norte.

Adida, Claire L. 2014. Immigrant Exclusion and Insecurity in Africa: Coethnic Strangers. Cambridge: Cambridge University Press.

Arcia, Adriana. 2014. Facebook Advertisements for Inexpensive Participant Recruitment Among Women in Early Pregnancy. Health Education \& Behavior 41(3): 237-41.

Auerbach, Adam Michael and Tariq Thachil. 2018. How Clients Select Brokers: Competition and Choice in India's Slums. American Political Science Review 112(4): 775-91.

Balcells, Laia and Gerard Torrats-Espinosa. 2018. Using a Natural Experiment to Estimate the Electoral Consequences of Terrorist Attacks. Proceedings of the National Academy of Sciences 115(42): 10624-9.

Bansak, Kirk, Jens Hainmueller, Daniel J. Hopkins, and Teppei Yamamoto. 2018. The Number of Choice Tasks and Survey Satisficing in Conjoint Experiments. Political Analysis 26(1): 112-9.

Branscombe, Nyla R. and Daniel L. Wann. 1994. Collective Self-Esteem Consequences of Outgroup Derogation When a Valued Social Identity is on Trial. European Journal of Social Psychology 24(6): 641-57.

Bridgman, Aengus, Costin Ciobanu, Aaron Erlich, Danielle Bohonos, and Christopher Ross. 2021. Unveiling: An Unexpected Mid-campaign Court Ruling's Consequences and the Limits of Following the Leader. Journal of Politics 83(3): 1024-9.

Bush, Sarah Sunn, and Amaney A. Jamal. 2015. Anti-Americanism, Authoritarian Politics, and Attitudes about Women's Representation: Evidence from a Survey Experiment in Jordan. International Studies Quarterly 59 (1): 34-45.

Chiozza, Giacomo. 2009. Anti-Americanism and the American World Order. John Hopkins University Press.

Chiozza, Giacomo. 2006. Disaggregating Anti-Americanism: An Analysis of Individual Attitudes Toward the United States. In Anti-Americanisms in World Politics, edited. Katzenstein, P. J. and Keohane, R. O. Ithaca, N.Y.: Cornell University Press, 93-126.

Christiansen, Connie Carøe. 2004. News Media Consumption among Immigrants in Europe: The Relevance of Diaspora. Ethnicities 4(2): 185-207.

Duncan, Felicity, Devra C. Moehler, and Laura R. Silver. 2015. Pro- and Anti-Americanism in SubSaharan Africa. International Journal of Public Opinion Research 27(2): 220-43.

Eady, Gregory and Charles Breton. 2021. Does International Terrorism affect Public Attitudes toward Refugees? Evidence from a Large-scale Natural Experiment. Journal of Politics. https://www.journals. uchicago.edu/doi/10.1086/714781. 
Ellemers, Naomi, Russell Spears, and Bertjan Doosje. 2002. Self and Social Identity. Annual Review of Psychology 53(1): 161-86.

Erlich, Aaron, Thomas Soehl, and Annie Y. Chen. 2021. Replication Data for: Discriminatory Immigration Bans Elicit Anti-Americanism in Targeted Communities: Evidence from Nigerian Expatriates. Harvard Dataverse, V3. doi: 10.7910/DVN/V8NM9T.

Feinstein, Yuval. 2016. Pulling the Trigger: How Threats to the Nation Increase Support for Military Action via the Generation of Hubris. Sociological Science 3: 317-34.

Finlayson, Alan. 1998. Ideology, Discourse and Nationalism. Journal of Political Ideologies 3(1): 99-118.

FitzGerald, David and David Cook-Martín. 2015. Culling the Masses: The Democratic Origins of Racist Immigration Policy in the Americas. Harvard University Press.

Jäger, Kai. 2017. The Potential of Online Sampling for Studying Political Activists Around the World and Across Time. Political Analysis 25(3): 329-43.

Jamal, Amaney A., Robert O. Keohane, David Romney, and Dustin Tingley. 2015. Anti-Americanism and Anti-Interventionism in Arabic Twitter Discourses. Perspectives on Politics 13(1): 55-73.

Joppke, Christian. 2005. Selecting by Origin: Ethnic Migration in the Liberal State. Cambridge, Mass.: Harvard University Press.

Kanno-Youngs, Zolan. 2020. Trump Administration Adds Six Countries to Travel Ban. The New York Times.

Legewie, Joscha. 2013. Terrorist Events and Attitudes toward Immigrants: A Natural Experiment. American Journal of Sociology 118(5): 1199-245.

Mattelart, Tristan. 2009. Les diasporas à l'heure des technologies de l'information et de la communication: petit état des savoirs. ticersociété 3(1-2).

Muñoz, Jordi, Albert Falcó-Gimeno, and Enrique Hernández. 2020. Unexpected Event during Survey Design: Promise and Pitfalls for Causal Inference. Political Analysis 28(2): 186-206.

OECD. 2015. Connecting with Emigrants. A Global Profile of Diasporas.

Ogen, Olukoya. 2017. Nigeria: Diaspora Engagement Policies in National Context. In Africa and Its Global Diaspora. Springer, 113-142.

Pew Research Centre. 2018. Trump's International Ratings Remain Low, Especially Among Key Allies.

Pötzschke, Steffen, and Michael Braun. 2017. Migrant Sampling Using Facebook Advertisements: A Case Study of Polish Migrants in Four European Countries. Social Science Computer Review 35(5): 633-53.

Rubinstein, Alvin Z. and Donale E. Smith. 1988. Anti-Americanism in the Third World. The Annals of the American Academy of Political and Social Science 497(1): 35-45.

Schachter, Ariela. 2016. From "Different" to "Similar" an Experimental Approach to Understanding Assimilation. American Sociological Review 81(5): 981-1013.

Schneider, Daniel, and Kristen Harknett. 2019. Consequences of Routine Work-Schedule Instability for Worker Health and Well-Being. American Sociological Review 84(1): 82-114.

Snyder, Jack, and Erica D. Borghard. 2011. The Cost of Empty Threats: A Penny, Not a Pound. American Political Science Review 105(3): 437-456.

Sokolov, Boris, Ronald F. Inglehart, Eduard Ponarin, Irina Vartanova, and William Zimmerman. 2018. Disillusionment and Anti-Americanism in Russia: From Pro-American to Anti-American Attitudes, 1993-2009. International Studies Quarterly 62(3): 534-547.

Waldinger, Roger. 2015. The Cross-Border Connection: Immigrants, Emigrants, and Their Homelands. Harvard University Press.

Zagheni, Emilio, Ingmar Weber, and Krishna Gummadi. 2017. Leveraging Facebook's Advertising Platform to Monitor Stocks of Migrants. Population and Development Review: 721-734.

Cite this article: Erlich A, Soehl T, and Chen AY (2023). Discriminatory Immigration Bans Elicit AntiAmericanism in Targeted Communities: Evidence from Nigerian Expatriates. Journal of Experimental Political Science 10, 76-87. https://doi.org/10.1017/XPS.2021.26 